\title{
Feasibility study on using solar chimney and earth-to-air heat exchanger for natural heating of buildings
}

\author{
Amin Haghighi Poshtiri ${ }^{1, *}$, Neda Gilani ${ }^{2}$, Farshad zamiri ${ }^{3}$ \\ ${ }^{I}$ Guilan University, Rasht, Iran \\ ${ }^{2}$ Tarbiat modares University, Tehran, Iran \\ ${ }^{3}$ Sharif university of technology, Tehran, Iran \\ * Corresponding author. Tel: +98 1316690273, Fax:+98 1316690271, E-mail: aminhaghighi_p@yahoo.com
}

\begin{abstract}
Here, the capability of the SC-EAHE system to meet the required thermal needs of individuals and also the dependence of the system performance on environmental and geometrical issues, have been studied. To determine the heat transfer characteristics of the system, a mathematical model based on energy conservation equations has been developed and solved by an iterative method. The results of study for the effect of air gap size variation on the air change per hour $(\mathrm{ACH})$ at various solar radiation values shows that this effect (air gap depth on the ACH) is significant up to $0.2(\mathrm{~m})$, and the ACH and room air temperature remains almost constant beyond the $0.2(\mathrm{~m})$. The results also revealed that the design of EAHE with the diameter of $0.5(\mathrm{~m})$ would lead to the best performance. It is found that, with proper insulation, SC system can provide thermal comfort condition even at the ambient temperature as low as $5{ }^{\circ} \mathrm{C}$ and the solar radiation intensity of $185\left(\mathrm{w} / \mathrm{m}^{2}\right)$.
\end{abstract}

Keywords: Solar chimney, Earth-to-air heat exchanger, Natural heating, Building.

\section{Nomenclature (Optional)}

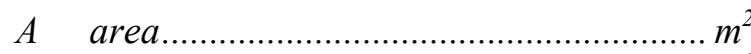

ACH air change per hour ............................... $h^{-1}$

C specific heat of air ........................... J/kgK

$c$ pressure loss coefficient of fittings ..............

$d \quad$ air gap depth, diameter ........................... $m$

$H$ distance................................................. $m$

$h$ convective heat transfer coefficient $\mathrm{W} / \mathrm{m}^{2} . \mathrm{K}$

$h r$ radiative heat transfer coefficient... W/m $\mathrm{m}^{2} . K$

I total solar radiation on surface .........W/ $/ \mathrm{m}^{2}$

$k \quad$ thermal conductivity ....................... W/m.K

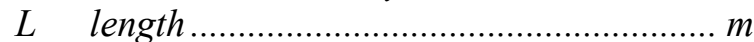

$m$ mass flow rate of air ........................... $\mathrm{kg} / \mathrm{s}$

$Q \quad$ heat transfer to air stream .................W/ ${ }^{2}$

$R \quad$ thermal resistance.............................. $m^{2} . K / W$

$r$ radius................................................. $m$

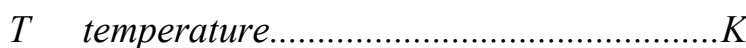

$t \quad$ thickness .................................................. $m$

$U$ overall heat transfer coefficient..... W/ $/ \mathrm{m}^{2} . K$

$u \quad$ air velocity ............................................ $\mathrm{m} / \mathrm{s}$

$V \quad$ volume of room .................................... $\mathrm{m}^{3}$

$x \quad$ coordinate system .................................... $m$

\section{Greek symbols}

$\alpha$ absorbtion coefficient $\gamma \quad$ constant in Eqs.(9) and,(10).....

$\delta \quad$ heat penetration depth.................................

$\varepsilon \quad$ emissivity.

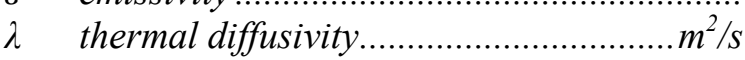

$\xi$ friction factor.

$\rho$ density......................................................

$\omega$ frequency of temperature oscillation.. $\mathrm{rad} / \mathrm{s}$

\section{Dimensionless terms}

$\mathrm{Nu}$ Nusselt number $h_{f \cdot} L / \mu_{f}$

\begin{tabular}{|c|c|}
\hline Sub & $\begin{array}{l}\text { scripts } \\
\text { ambient }\end{array}$ \\
\hline$a b s$ & absorber wall... \\
\hline$f$ & air flow ................ \\
\hline$g$ & glass....... \\
\hline hyd & hydraulic... \\
\hline$i$ & internal... \\
\hline$r$ & room ..... \\
\hline$S$ & soil ........... \\
\hline$s u$ & undisturbed soil. \\
\hline$t$ & 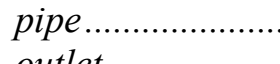 \\
\hline
\end{tabular}

\section{Introduction}

Traditional energy resources such as fossil fuels which lead to the greenhouse effect, global warming, are expected to dwindle gradually. As environmental regulations are becoming strict, further investigation on alternative solutions to meet the energy needs of residential 


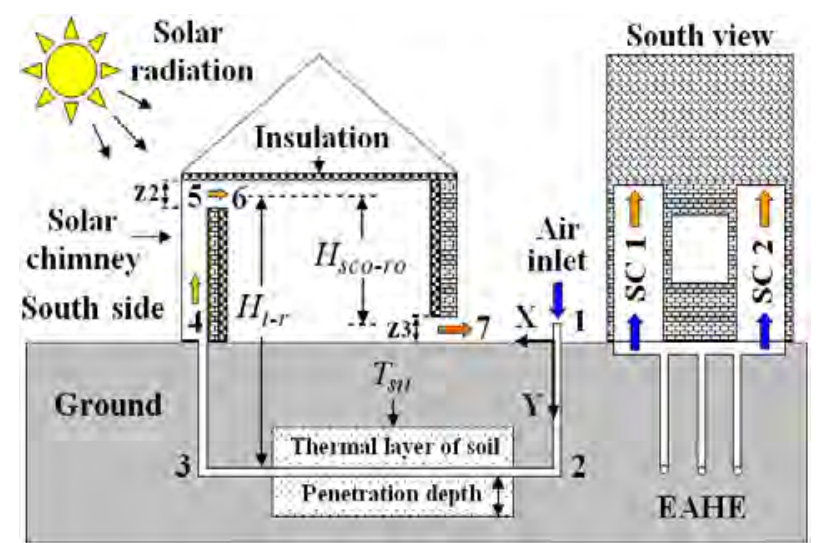

Fig. 1. Schematic diagram of integrated EAHE and SC.

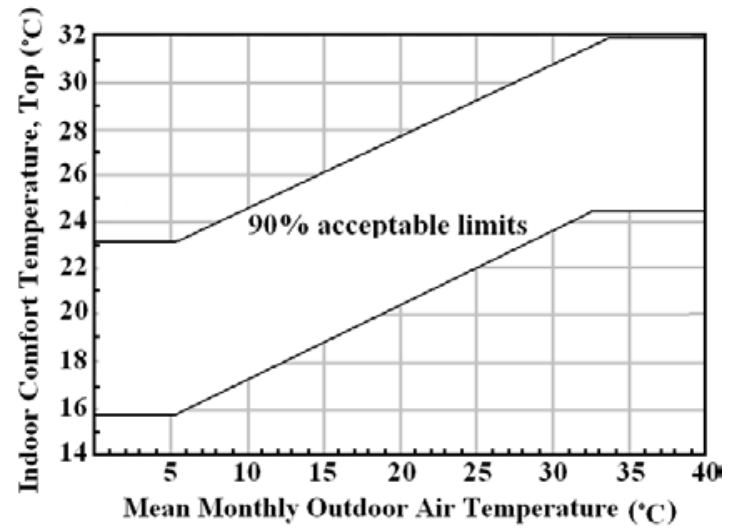

Fig. 2. Adaptive Comfort standard.

units as well as industrial ones is also on the table. The use of passive techniques is an effective tool for attenuating the growth of the energy consumption for air conditioning. Earth to air heat exchanger (EAHE) and solar chimney (SC) are passive heating systems which are commonly used for reducing energy consumption.

Many researches have been conducted on using EAHE for producing cool or warm air so far. Hollmuller [1] considered a periodic input for the air in the buried pipe, yielding a physical interpretation of the amplitude-dampening and the phase-shifting of the periodic input signal. Al-Ajmi et al. [2] developed a theoretical model of an EAHE for predicting the outlet air temperature and cooling potential of these devices. They showed that it have the potential for reducing cooling energy demand in a typical house by 30\% over the peak summer season.

Solar chimneys have attracted much attention of researchers. Bansal et al. [3] analytically studied a solar chimney-assisted wind tower for natural ventilation in buildings. The estimated effect of the solar chimney was shown to be substantial in inducing natural ventilation for low wind speeds. Gan and Riffat [4] also investigated solar assisted natural ventilation with heat-pipe heat recovery in naturally ventilated buildings, using a CFD technique. Mathur et al. [5] analytically studied the effect of absorber inclination on the air flow rate in a solar induced ventilation system using roof solar chimney. The results showed that optimum absorber inclination depending upon the latitude of the location. Maerefat and Haghighi [6] introduced and investigated integrated EAHE-SC system. They showed that the solar chimney can be perfectly used to power the underground cooling system during the daytime, without any need for electricity. The review of the related literature shows that the combination of EAHE and SC as a heating system has not been fully investigated yet.

Fig.1 illustrates a schematic plan of the system. The solar chimney comprises a glass surface oriented to the south and an absorber wall which acts as a capturing surface. The EAHE consists of horizontal long pipe that is placed underground. The air is heated up in the SC by the solar energy, and by natural convection mechanism the outside air is sucked-in through the pipe. It will be shown that this system can provide good indoor condition in accordance with the Adapted Comfort Standard (ACS). The required indoor temperatures according to the adaptive comfort model are shown in Fig. 2. ACS does not recommend the ventilation rate [7]. Therefore, the minimum ventilation rate is set around $3 \mathrm{ACH}$ [8]. 


\section{Problem formulation}

The modeling includes models of earth to air heat exchanger (Fig. 3) and solar chimney Fig. 4). The following assumptions are made in this analysis.

1. Only buoyancy force is considered, wind induced natural ventilation is not included.

2 . The flows in the channels are hydro dynamically and thermally fully developed.

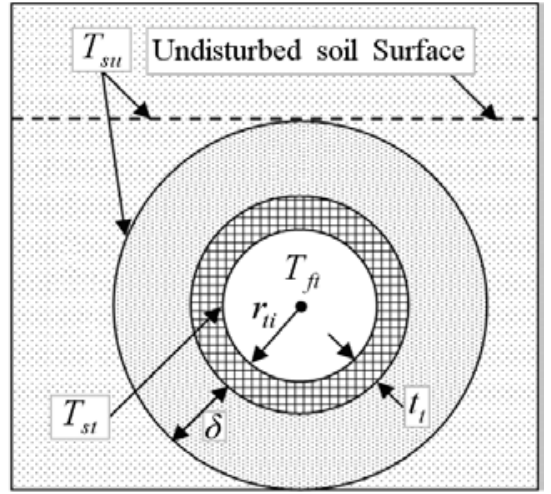

Fig. 3. Cross section of an EAHE.

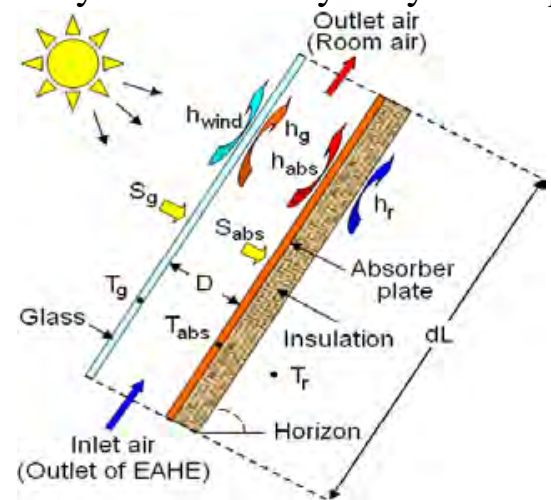

Fig. 4. Diagram of the heat transfer in the SC.

3. The glass cover is opaque for infrared radiation.

4. Thermal capacities of glass and absorber wall are negligible.

5. The air flow in the channel is radiation non-participating media.

6. The soil is homogeneous and the soil type does not change along the channel.

7. The system is at steady-state condition.

\subsection{Mathematical modeling of EAHE}

The cross section of EAHE used in the model is shown in Fig. 3. In order to impose the ground thermal loads as boundary conditions at the EAHE wall, the undisturbed soil temperature $\left(T_{s u}\right)$ has been used. The soil temperature is nearly constant at the penetration depth. It is defined when the surface of the soil is subjected to a periodic temperature [1]. $\delta=\sqrt{2 \lambda_{s} / \omega}$

The air temperature through the EAHE is calculated by the following equation [6].

$T_{f t}(x)=T_{s u}+\left(T_{a}-T_{s u}\right) \exp \left(-x /\left(m C_{f t} R_{\text {total }}\right)\right)$

Where $R_{\text {total }}$ represents the overall thermal resistance and is given by [6]:

$R_{\text {total }}=\frac{1}{2 \pi L_{t}}\left(1 / h_{f t}+\ln \left(\frac{r_{t i}+t_{t}}{r_{t i}}\right) / k_{t}+\ln \left(1+\frac{\delta}{r_{t i}+t_{t}}+\sqrt{\left(1+\frac{\delta}{r_{t i}+t_{t}}\right)^{2}-1}\right) / k_{s}\right)$

\subsection{Mathematical modeling of SC}

An element of the model for SC is shown in Fig. 4. In principle and based on the energy conservation law, a set of differential equations are obtained along the length of SC [6].

The energy balance equation for glass cover is:

$\alpha_{g} I A_{g}+h r_{a b s-g} A_{a b s}\left(T_{a b s}-T_{g}\right)=h_{g} A_{g}\left(T_{g}-T_{f s c}\right)+U_{g-a} A_{g}\left(T_{g}-T_{a}\right)$

The overall top heat loss coefficient from glass cover to ambient $\operatorname{air} U_{g-a}$, can be written as:

$U_{g-a}=h_{\text {wind }}+h r_{g-s k y}+h_{g-a}$

The convective heat transfer coefficient due to the wind is $h_{\text {wind }}=2.8+3.0 u_{\text {wind }}$ [9]. 
The radiative heat transfer coefficient from the outer glass surface to the sky and between absorber plate and glass cover may be obtained from [9]:

$$
\begin{aligned}
& h r_{g-s k y}=\sigma \varepsilon_{g}\left(T_{g}+T_{s k y}\right)\left(T_{g}^{2}+T_{s k y}^{2}\right)\left(T_{g}-T_{s k y}\right) /\left(T_{g}-T_{a}\right) \\
& h r_{a b s-g}=\sigma\left(T_{g}^{2}+T_{a b s}^{2}\right)\left(T_{g}+T_{a b s}\right) /\left(1 / \varepsilon_{g}+1 / \varepsilon_{a b s}-1\right)
\end{aligned}
$$

Where, the sky temperature is $T_{s k y}=0.0552 T_{a}^{1.5}[9]$.

The convective heat transfer coefficient is given by: [5]:

$h=\mathrm{Nu} k_{f s c} / L$

All property values are evaluated at average surface - air temperatures.

The energy balance equation for air flow in the chimney is:

$h_{a b s} A_{a b s}\left(T_{a b s}-T_{f s c}\right)+h_{g} A_{g}\left(T_{g}-T_{f s c}\right)=-m C_{f s c}\left(T_{f s c}-T_{f t o}\right) / \gamma$

The mean air temperature was experimentally determined to follow the non-linear form [10]:

$T_{f s c}=\gamma T_{f s c o}+(1-\gamma) T_{f s c i n}$

Value of the constant $\gamma$ is taken as 0.74 according to Ref. [10].

The energy balance equation for the absorber plate is written as:

$\alpha_{a b s} I A_{a b s}=h_{a b s} A_{a b s}\left(T_{a b s}-T_{f s c}\right)+h r_{a b s-g} A_{a b s}\left(T_{a b s}-T_{g}\right)+U_{a b s-r} A_{a b s}\left(T_{a b s}-T_{r}\right)$

The overall heat transfer coefficient from the absorber wall to the room $U_{a b s-a}$ is given by:

$U_{a b s-r}=1 /\left(1 / h_{r}+t_{\text {ins }} / k_{\text {ins }}\right)$

In the above equation $h_{r}$ has been taken as $2.8 \mathrm{~W} / \mathrm{m}^{2} \mathrm{~K}[10]$.

\subsection{Room ventilation and temperature}

The buoyancy pressure due to increasing air temperature in SC, sucks the air through the EAHE. The friction losses due to fluid flow through the channels and across the fittings, refrain from the fluid flow. If the buoyancy pressure overcomes the sum of all flow pressure losses, the natural ventilation may take place.

A mathematical model based on Bernoulli's equation has been used to estimate the system flow rate. Thus, the chimney net draft can be calculated by the following equation:

$$
\text { Draft }_{s c}=\left(\rho_{f t o}-\rho_{f s c o}\right) g L_{s c}-\left(\sum_{j=5}^{6} c_{j}+\xi_{s c} \frac{L_{s c}}{\left(d_{h y d}\right)_{s c}}\right)\left(\frac{\rho_{f s c o} u_{s c}^{2}}{2}\right)
$$

Where the $c_{j}$ is the pressure loss coefficients at the locations which are indicated in Fig. 1.

The EAHE pressure loss $\Delta P_{E A H E}$ is:

$$
\Delta P_{E A H E}=\left(\sum_{j=1}^{4} c_{j}+\xi_{t} \frac{L_{E A H E}}{d_{\text {tin }}}\right)\left(\frac{\rho_{f t} u_{f t}^{2}}{2}\right)
$$

The chimney effects Draft $t_{E A H E}$ and Draft $t_{\text {Room }}$ can be expressed as:

$$
\begin{aligned}
& \operatorname{Draft}_{E A H E}=\left(\rho_{f a}-\rho_{f t}\right) g\left(H_{t-r}-L_{s c}\right) \\
& \text { Draft }_{r}=\left(\rho_{f r}-\rho_{f s c o}\right) g H_{s c o-r o}
\end{aligned}
$$

The required draft for heating system Draft $_{\text {System }}$ is the sum of the pipe pressure loss and the positive pressure Draft $_{E A H E}$ and Draft ${ }_{\text {Room }}$.

$$
\text { Draft }_{\text {System }}=\Delta P_{\text {EAHE }}+\text { Draft }_{\text {EAHE }}+\text { Draft }_{r}
$$

Under steady-state conditions, we can write:

$$
\text { Draft }_{\text {System }}=\text { Draft }_{\text {sc }}
$$


The air mass flow rate at the chimney and EAHE are the same if there is no air infiltration:

$m=\left.\rho A u\right|_{\text {Chimney outlet }}=\left.\rho A u\right|_{\text {Chimney inlet }}=\left.\rho A u\right|_{\text {EAHE }}$

By expanding equation (18), the air velocity in the SC can be obtained as:

Table 1. Comparison of experimental and theoretical results for solar chimney included ACH No.

\begin{tabular}{|c|c|c|c|c|c|c|c|c|}
\hline \multirow{2}{*}{$\begin{array}{c}\text { Solar } \\
\text { radiation } \\
\left(\mathrm{W} / \mathrm{m}^{2}\right)\end{array}$} & \multirow{2}{*}{$\begin{array}{l}\text { Absorber } \\
\text { Length } \\
\text { (m) }\end{array}$} & \multirow{2}{*}{$\begin{array}{l}\text { Inlet chim. } \\
\text { Dimens } \\
(\mathrm{m} \times \mathrm{m})\end{array}$} & \multirow{2}{*}{$\begin{array}{c}\text { Ambient } \\
\text { temp. } \\
(\mathrm{K})\end{array}$} & \multicolumn{3}{|c|}{$\mathrm{ACH}$} & \multirow{2}{*}{$\begin{array}{c}\text { Errors } \\
\text { of } \\
{[10]} \\
(\%)\end{array}$} & \multirow{2}{*}{$\begin{array}{c}\text { Errors } \\
\text { of } \\
\text { present } \\
\text { study } \\
(\%)\end{array}$} \\
\hline & & & & $\begin{array}{l}\text { Exp. } \\
{[10]}\end{array}$ & $\begin{array}{l}\text { Theo. } \\
\text { [10] }\end{array}$ & $\begin{array}{l}\text { Theo. } \\
\text { (present } \\
\text { study) }\end{array}$ & & \\
\hline 500 & 0.8 & $1.0 \times 0.2$ & $298-304$ & 4.53 & 4.89 & 4.68 & 7.95 & 3.31 \\
\hline 500 & 0.9 & $1.0 \times 0.1$ & 294-296 & 2.66 & 3.46 & 3.44 & 30.07 & 29.32 \\
\hline 700 & 0.8 & $1.0 \times 0.2$ & 298-304 & 5.33 & 5.17 & 5.31 & 3.00 & 0.37 \\
\hline 700 & 0.9 & $1.0 \times 0.1$ & 294-296 & 2.93 & 3.67 & 3.32 & 25.25 & 13.31 \\
\hline
\end{tabular}

$u_{s c}=\sqrt{\text { Bouyancy Terms / Friction Terms }}$

Buoyancy Terms $=2\left\{\begin{array}{l}\left(\rho_{f t o}-\rho_{f s c o}\right) g L_{s c}-\left(\rho_{f a}-\rho_{f t}\right) g\left(H_{t-r}-L_{s c}\right)- \\ \left(\rho_{f r}-\rho_{f s c o}\right) g H_{s c o-r o}\end{array}\right\}$

Friction Terms $=(c)_{7}\left(\frac{\rho_{f s c o} A_{s c o}}{\rho_{f r} A_{r o}}\right)^{2} \rho_{f r}+\left\{(c)_{5}+(c)_{6}+\xi_{s c} \frac{L_{s c}}{\left(d_{h y d}\right)_{s c}}\right\} \rho_{f s c o}+$

$$
\left\{\left(\sum_{j=1}^{4} c_{j}+\xi_{t} \frac{L_{t}+2\left(H_{t-r}-L_{s c}\right)}{d_{t}}\right)\left(\frac{\rho_{f s c o} A_{s c o}}{\rho_{f t} A_{t}}\right)^{2}\right\} \rho_{f t}
$$

The ACH is calculated under steady-state conditions by the following equation [10]:

$A C H=3600 m /\left(\rho_{s s c} V\right)$

The room air temperature which depends on room heat gain is given by:

$T_{r}=T_{\text {fscout }}-Q_{r} /\left(m C_{f r}\right)$

Where $Q_{r}$ is sum of the heats that the room gains through the walls and the heat generated by internal heat sources.

The coupled governing equations (2), (4), (9), (11) and (20) are the full description of the system and have to be solved iteratively until convergence of the results.

\section{Model validation}

There is no experimental data to validate the results of theoretical model for the integrated system. So, the calculation has been carried out for SC and EAHE separately under same conditions of experimental studies of [10] and [11]. Table 1 shows the results of present model and the theoretical and experimental results of Mathur et al. [10]. The quantitative comparison shows a reasonable agreement between the results obtained by the present study and the published results of [10]. The results of present study are closer to the experimental results than the theoretical results of Ref. [10]. It should be noted that the calculation carried out at the same conditions of Ref. [10] in which the room volume is $27.0\left(\mathrm{~m}^{3}\right)$. Fig. 5 shows the air temperature variation along the cooling pipe. The results of the present work are calculated at the conditions of experiments based on Ref. [11]. As the figure shows, there is good agreement between the present theoretical results and the experimental results of Ref. [11]. However, it is reasonable to conclude that the mathematical model can predict air temperature quite accurately and the calculated results are reliable. 


\section{Results and discussion}

The following dimensions and specifications are used in the modeling. The room has size of

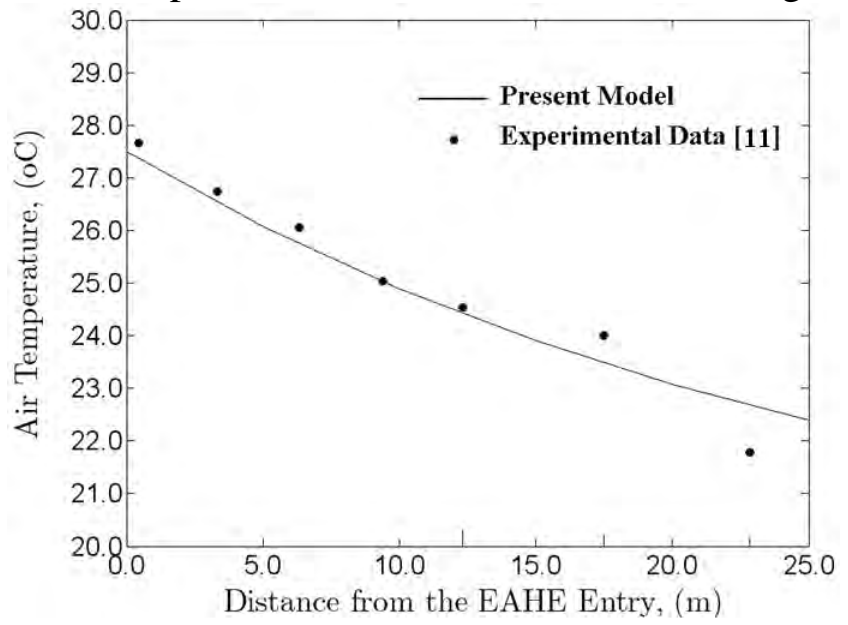

Fig. 5. Comparison present results with experimental data.

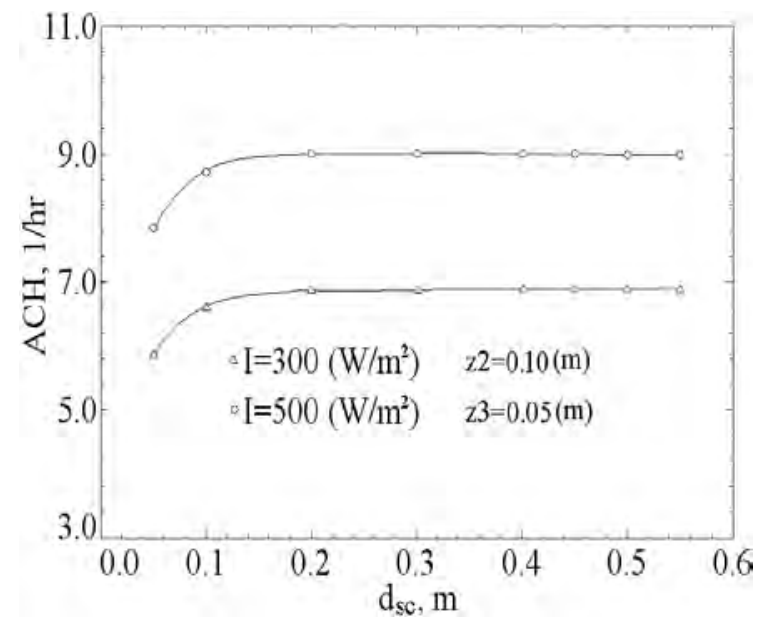

Fig. 6. ACH variation with changes of air gap depth of $S C\left(T_{a}=10^{\circ} \mathrm{C}\right)$.

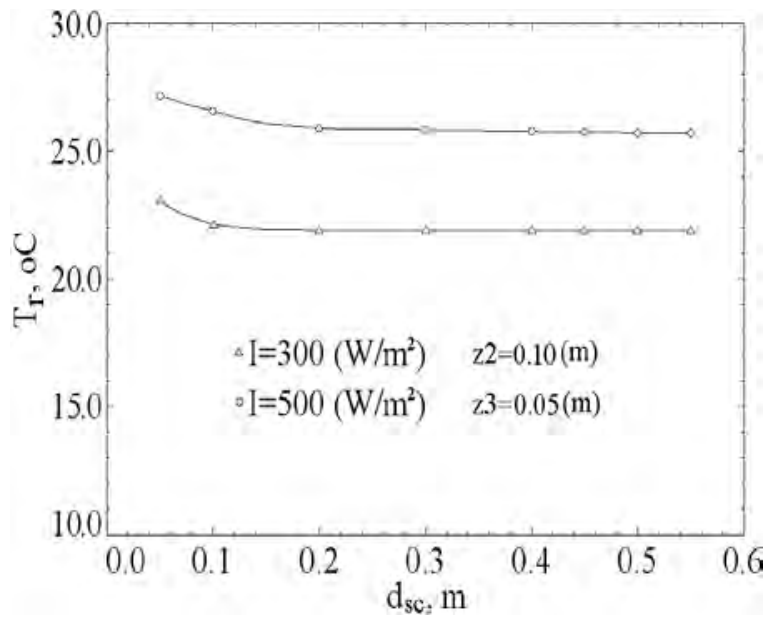

Fig. 7. Room air temperature variation with changes of air gap depth of $S C\left(T_{a}=10^{\circ} \mathrm{C}\right)$.

$4.0(\mathrm{~m}) \times 4.0(\mathrm{~m}) \times 3.125(\mathrm{~m})$ without air infiltration. The heating demand is assumed to change within the range of $0.0-1000(\mathrm{~W})$ in the calculations. A solar chimney with the length of 3.125 (m), width of $4.0(\mathrm{~m})$ and air gap depth of $0.2(\mathrm{~m})$ is considered. The thickness and thermal conductivity of the insulation located in south wall of the room are $0.2(\mathrm{~m})$ and 0.046 $\left(\mathrm{Wm}^{-1} \mathrm{~K}^{-1}\right)$, respectively. The transmissivity of the glass wall is 0.84 and the absorber wall has an emissivity and absorptivity equal to 0.95 . The outlet sizes of SC and room (Fig. 1) are $0.05(\mathrm{~m}) \times 4.0(\mathrm{~m})$ and $0.1(\mathrm{~m}) \times 4.0(\mathrm{~m})$ respectively. The heating pipe of EAHE is a PVC pipe with $25.0(\mathrm{~m})$ length, $0.01(\mathrm{~m})$ thickness, and inside diameter of $0.5(\mathrm{~m})$ and is buried $3.0(\mathrm{~m})$ below the soil surface. The initial soil temperature at it, is approximated to be $19^{\circ} \mathrm{C}$ for a dry shaded soil surface condition and it is considered to be the heat source temperature.

\subsection{Effective dimensions of the system}

There are many geometrical dimensions which affect the system performance: i) air gap depth of the SC, ii) heating surface area of the EAHE. Fig. 6 shows the effect of air gap size variation on the ACH. It shows that the effect of air gap depth on the ACH is significant up to 0.2 (m) and, the ACH remains almost constant beyond 0.2 (m). Fig. 7 shows that as the air 
gap depth increases, the room air temperature decreases gradually. This decrease is due to the result of increasing the $\mathrm{ACH}$ which causes reduction in the energy gained by the absorber. A comparison between these figures shows that as the chimney air gap size increases up to almost $0.2(\mathrm{~m})$, any further increase does not have a significant effect on room air temperature and it is considered as an optimum required value of the air gap.

Table 2. Effects of diameter of EAHE on system performance.

\begin{tabular}{cccccccc}
\hline $\begin{array}{c}\text { Heating } \\
\text { demand } \\
(\mathrm{W})\end{array}$ & $\begin{array}{c}\text { Solar } \\
\text { radiation } \\
\left(\mathrm{W} / \mathrm{m}^{2}\right)\end{array}$ & $\begin{array}{c}\text { Ambient } \\
\text { air temp. } \\
\left({ }^{\circ} \mathrm{C}\right)\end{array}$ & $\begin{array}{c}\text { Length } \\
\text { of EAHE } \\
(\mathrm{m})\end{array}$ & $\begin{array}{c}\text { Diameter } \\
\text { of EAHE } \\
(\mathrm{m})\end{array}$ & $\begin{array}{c}\text { ACH } \\
\text { air temp. } \\
\left({ }^{\circ} \mathrm{C}\right)\end{array}$ & $\begin{array}{c}\text { Number of SC } \\
\text { and EAHE }\end{array}$ \\
\hline 0 & 300 & 10 & 25 & 0.3 & 3.82 & 27.2 & 1 \\
0 & 300 & 10 & 25 & 0.5 & 6.85 & 21.9 & 1 \\
0 & 300 & 10 & 25 & 0.7 & 7.72 & 20.7 & 1 \\
500 & 300 & 10 & 25 & 0.3 & Thermal comfort cannot be provided. \\
500 & 300 & 10 & 25 & 0.5 & 5.04 & 20.0 & 1 \\
500 & 300 & 10 & 25 & 0.7 & 5.74 & 18.5 & 1 \\
\hline
\end{tabular}

Table 3. Effects of length of EAHE on system performance.

\begin{tabular}{cccccccc}
\hline $\begin{array}{c}\text { Heating } \\
\text { demand } \\
(\mathrm{W})\end{array}$ & $\begin{array}{c}\text { Solar } \\
\text { radiation } \\
\left(\mathrm{W} / \mathrm{m}^{2}\right)\end{array}$ & $\begin{array}{c}\text { Ambient } \\
\text { air temp. } \\
\left({ }^{\circ} \mathrm{C}\right)\end{array}$ & $\begin{array}{c}\text { Length } \\
\text { of EAHE } \\
(\mathrm{m})\end{array}$ & $\begin{array}{c}\text { Diameter } \\
\text { of EAHE } \\
(\mathrm{m})\end{array}$ & $\begin{array}{c}\text { ACH } \\
\text { air temp. } \\
\left({ }^{\circ} \mathrm{C}\right)\end{array}$ & $\begin{array}{c}\text { Number of SC } \\
\text { and EAHE }\end{array}$ \\
\hline 0 & 300 & 10 & 25 & 0.5 & 6.85 & 21.9 & 1 \\
0 & 300 & 10 & 35 & 0.5 & 6.35 & 23.2 & 1 \\
0 & 300 & 10 & 45 & 0.5 & 5.89 & 24.4 & 1 \\
500 & 300 & 10 & 25 & 0.5 & 5.04 & 20.0 & 1 \\
500 & 300 & 10 & 35 & 0.5 & 4.73 & 21.3 & 1 \\
500 & 300 & 10 & 45 & 0.5 & Thermal comfort cannot be provided. \\
\hline
\end{tabular}

In order to increase the heating surface one may increase the diameter and/or the length of the pipe. Table 2 shows the effect of EAHE diameter on system performance. A comparative survey shows that that as the diameter of EAHE increases up to almost $0.5(\mathrm{~m})$, any further increase does not have a significant effect on $\mathrm{ACH}$ and room air temperature. Therefore this value is adopted as default value of diameter. Table 3 shows the effect of EAHE length on system performance. For the length of EAHE more than 35 (m), the comfort temperature may not be provided and smaller EAHE should be employed.

\subsection{Effect of environmental conditions on the system performance}

The results of Table 4 also show that when air temperature rises, thermal comfort can be achieved in lower solar radiation. It is also found that when the heating demand is high, thermal comfort can be achieved only at high solar radiation. However, with proper insulation and reduction of the heating demand, SC can provide good indoor condition in the poor solar intensity and low ambient air temperature. The results show that when the heating demand is low, SC can provide thermal comfort condition even when the ambient temperature and solar intensity are equal to $5{ }^{\circ} \mathrm{C}$ and $185 \mathrm{w} / \mathrm{m}^{2}$, respectively.

\section{Conclusions}

Natural ventilation and heating of a room which uses SC and an EAHE have been studied in this paper. The results show that there is an optimum size for air gap size of SC $(0.2(\mathrm{~m}))$ and diameter of heating pipe $(0.5(\mathrm{~m}))$. It has been found that the long EAHE with the length of 
less than 35 (m) should be employed to provide the thermal comfort condition. The results also show that when the ambient temperature is low, although providing thermal comfort is difficult, proper configurations could provide good indoor condition even in the poor solar intensity.

Table 4. System performance at different indoor and outdoor conditions.

\begin{tabular}{cccccccc}
\hline $\begin{array}{c}\text { Heating } \\
\text { demand } \\
(\mathrm{W})\end{array}$ & $\begin{array}{c}\text { Solar } \\
\text { radiation } \\
\left(\mathrm{W} / \mathrm{m}^{2}\right)\end{array}$ & $\begin{array}{c}\text { Ambient } \\
\text { air temp. } \\
\left({ }^{\circ} \mathrm{C}\right)\end{array}$ & $\begin{array}{c}\text { Length of } \\
\text { EAHE } \\
(\mathrm{m})\end{array}$ & $\begin{array}{c}\text { Diameter } \\
\text { of EAHE } \\
(\mathrm{m})\end{array}$ & $\begin{array}{c}\text { ACH } \\
\begin{array}{c}\text { Room air } \\
\text { temp. } \\
\left({ }^{\circ} \mathrm{C}\right)\end{array}\end{array}$ & $\begin{array}{c}\text { Number of } \\
\text { SC and } \\
\text { EAHE }\end{array}$ \\
\hline 0 & 400 & 0 & 15 & 0.5 & 8.59 & 15.9 & 1 \\
0 & 250 & 0 & 25 & 0.5 & 5.11 & 15.9 & 1 \\
0 & 250 & 5 & 15 & 0.5 & 6.28 & 17.5 & 1 \\
0 & 185 & 5 & 25 & 0.5 & 3.45 & 17.5 & 1 \\
500 & 560 & 0 & 15 & 0.5 & 8.59 & 15.9 & 1 \\
500 & 550 & 0 & 25 & 0.5 & 8.47 & 15.9 & 1 \\
500 & 390 & 5 & 15 & 0.5 & 6.79 & 17.5 & 1 \\
500 & 320 & 5 & 25 & 0.5 & 5.67 & 17.5 & 1 \\
1000 & - & 0 & 15 & Thermal comfort cannot be provided. & \\
1000 & - & 0 & 25 & Thermal comfort cannot be provided. & \\
1000 & 500 & 5 & 15 & 0.5 & 6.26 & 17.5 & 1 \\
1000 & - & 5 & 25 & Thermal comfort cannot be provided. & \\
\hline
\end{tabular}

\section{References}

[1] P. Hollmuller, Analytical characterization of amplitude-dampening and phase shifting in air/soil heat exchangers. International Journal of Heat and Mass Transfer 46, 2003, pp.4303-4317.

[2] F. Al-Ajmi, DL. Loveday, VI. Hanby, The cooling potential of earth-air heat exchangers for domestic buildings in a desert climate, Building and Environment 41, 2006, pp. 235244.

[3] NK. Bansal, R. Mathur, MS. Bhandari, A study of solar chimney assisted wind tower system for natural ventilation in buildings, Building and Environment 29(4), 1994, pp. 495-500.

[4] G. Gan, SB. Riffat, A numerical study of solar chimney for natural ventilation of buildings with heat recovery, Applied Thermal Engineering 18, 1998, pp. 117-187.

[5] J. Mathur, S. Mathur, Anupma, Summer-performance of inclined roof solar chimney for natural ventilation, Energy and Buildings 38, 2006, pp. 1156-1163.

[6] M. Maerefat, AP. Haghighi, passive cooling of building by using integrated earth to air heat exchanger and solar chimney, Renewable Energy 35, 2010, pp. 2316-2324.

[7] GS. Brager, RJ. De dear, A standard for natural ventilation, ASHRAE Journal 42(10), 2000, pp. 21-28.

[8] BIS, Bureau of Indian Standards, Handbook of Functional Requirements of Buildings 1997 ISBN81-7061-011-7.

[9] KS. Ong, A mathematical model of a solar chimney, Renewable Energy 28, 2003, pp. 1047-1060.

[10]J. Mathur, NK. Bansal, S. Mathur, M. Jain, Experimental investigations on solar chimney for room ventilation, Solar Energy 80, 2006, pp. 927-935.

[11] As. Dhaliwal, DY. Goswami, Heat transfer analysis in environmental control using an underground air tunnel, Journal of Solar Energy Engineering 107, 1985, 141-145. 